\title{
Modelling of Biomass Pyrolysis in a Bubbling Fluidized Bed reactor: Impact of Intra-particle Heat Conduction
}

\author{
N.H. Dong ${ }^{1, *}$, K.H. Luo ${ }^{2}$, Q. Wang ${ }^{1, *}$ \\ 1. School of Energy and Power Engineering, Northeast Dianli University, Jilin 132012, China \\ 2. Department of Mechanical Engineering, University College London, London WC1E 7JE, UK \\ *Corresponding authors. \\ N.H.Dong@ nedu.edu.cn (N.H. Dong) \\ rlx888@126.com (Q. Wang)
}

\begin{abstract}
Biomass fast pyrolysis in a fluidized bed reactor is studied numerically by a three-fluid model where the biomass thermal decomposition is introduced with multi-step kinetics. Different superficial velocities of fluidizing gas are defined to investigate the hydrodynamics of the fluidized beds and the consequent influence on the yield fractional distribution of end-products. Heat conduction inside particles is considered indirectly through modifying the rate constants of biomass reaction scheme. The simulation results show that superficial velocity has to be designed carefully based on balancing the char-removal efficiency and biomass heating up rate; compared to the experimental data, the modified reaction scheme can be employed to describe the intra-particle heat penetration, qualitatively, and however the accuracy on predicting the end-product yields needs to be improved.
\end{abstract}

Keywords:

Biomass fast pyrolysis; Fluidized bed reactor; Intra-particle heat penetration 


\section{Introduction}

Fast pyrolysis of biomass has been studied extensively due to the interests on the primary end-product, namely tar or bio-oil. A series of works on biomass pyrolysis mechanism have been reported [1,2] and the end-products are analyzed [3,4]. Numerical simulation is a useful tool to aid the design of biomass pyrolysis reactors. The product yields of biomass pyrolysis are predicted by the two-fluid model (TFM) coupling with the multi-component reaction scheme and the simulation results are validated experimentally [5,6]. The Boltzmann equation accounting for the collisional transfer between particles in a fluidized bed has been introduced into the modeling of biomass thermal degrading. The improved prediction of the fractional distribution of end-products can be expected [7]. One or several biomass particles are identified in the computational fluid dynamics-discrete element method (CFD-DEM) modeling of biomass fast pyrolysis to study the flow characteristics of fluidized beds and the yields of end-products. Although the number of the traced particles is limited, the evolution of the reacting particles has been studied in detail such as intra-particle heat conduction, particle shrinkage and particle entrainment in gas flow [8-11]. Two different reaction schemes including the single-component model and the detailed chemistry scheme are introduced into the 3D simulations. In the latter scheme, biomass can be written as $\mathrm{C}_{6} \mathrm{H}_{8.46} \mathrm{O}_{3.9}$ while the products of the primary reaction are addressed with the reference species including Phenol, Acetone, Acrylic-acid, etc $[12,13]$. Different reaction schemes have been employed into the simulations of biomass fast pyrolysis meanwhile the parametric study reveals the effect of biomass particle type and size on the yields of the products[14]. Modeling of red oak pyrolysis in a bubbling fluidized bed is reported and the impact of hydrodynamics of bubbling fluidized bed on tar yield is investigated numerically by changing the sand size and sand bed height[15]. Particle size distribution (PSD) is investigated through Eulerian-Eulerian CFD modeling in which the PSD model would be more realistic than the mono-particle size model on describing the motion of real particles [16]. For large particles, the temperature gradient due to the intra-particle heat conduction 
cannot be neglected and will lead to the variation of local reaction rate. To consider the heat penetration process, thermal conductivity of wood has been specified by an effective thermal conductivity which is a function of temperature, density and moisture [17]. It is clear that the representation of mass and heat transfer on the particle scale is practical by Lagrangian approaches whereas the direct inspection is impossible for Eulerian approaches. Hence incorporating empirical correlation into chemical kinetics is proposed to describe the effect of intra-particle heat conduction on the product yields [18]. As the intra-particle heat penetration is seldom considered in the modeling of biomass pyrolysis, the present work is trying to employ the Eulerian approaches to investigate the corn stalk fast pyrolysis in a bubbling fluidized bed. Meanwhile the impact of intra-particle heat penetration is considered by the modified chemical kinetics and the simulation results are validated with the experimental data.

\section{Model setup}

\subsection{Model geometry}

The 2D geometry is set up with the diameter of $100 \mathrm{~mm}$ and height of $600 \mathrm{~mm}$ (Figure 1). Sand particles are pre-loaded above the bottom distributor with the initial bed height of $50 \mathrm{~mm}$ and packing rate of 0.63. Sand and biomass particles are defined as perfect spheres with the uniform diameter of $0.4 \mathrm{~mm}$. PSD of the real samples is not emphasized in the current work. Biomass samples are injected by hot nitrogen from the side-inlet point (inlet 1) and the sand particles are fluidized by hot nitrogen from the bottom distributor (inlet 0). Biomass composition is followed with the analysis of corn stalk samples: cellulose of $37.6 \mathrm{wt} . \%$, hemi-cellulose of $21.6 \mathrm{wt} . \%$ and lignin of 18.4 wt.\% [19]. As no extractives is presented in the simulations, the mass fractions of the three pseudo-components are translated to $48.5 \mathrm{wt} . \%, 27.8 \mathrm{wt} . \%$ and 23.7 wt.\%, approximately. The gas and solid physical properties are given in Table 1.

\subsection{Numerical model setup}

In the current work, a three-fluid model is constructed including one gas phase 
and two solid phases of sand and biomass. All of the solid phases are treated as interpenetrating continua with individual volume fractions. The gas phase is a mixture of $n_{2}$, tar and syngas. Meanwhile one of the solid phases, $s_{1}$, is a mixture of biomass and char with the initial fractions of 1 and 0 , respectively. The other solid phase, $s_{2}$, is sand. The multi-step kinetics of biomass fast pyrolysis is shown in Figure 2 and the relevant reaction constants are given at Table 2 [7].

\subsection{Mathematical model setup}

The three-fluid model is extended by two-fluid model (TFM) with an additional solid phase. The governing equations have to be completed with the consideration of interactions between solid phases. The momentum exchange between the gas and solid phases is calculated by Gidaspow model [20] meanwhile that between solid phases is considered by Syamlal model [21]. The mass transfer in reactions is defined by the mass changes of different species. The consequent variations are presented in the momentum and energy conservation equations. The governing equations are summarized as follows.

\section{Gas phase.}

The species mass fraction is solved separately to represent the species mass balance:

$\frac{\partial}{\partial t}\left(\alpha_{g} \rho_{g} Y_{i}\right)+\nabla \cdot\left(\alpha_{g} \rho_{g} \vec{v}_{g} Y_{i}\right)=\dot{M}_{i}$

where $\alpha_{g}, \rho_{g}, \mathrm{Y}_{\mathrm{i}}, \vec{v}_{g}, \dot{\mathrm{M}}_{\mathrm{i}}$ are the local mass fraction, density, velocity of gas and the net production rate of species $\mathrm{i}, \mathrm{i}=1,2, \ldots, \mathrm{n}$, respectively.

The mass conservation of gas phase is written as

$\frac{\partial}{\partial t}\left(\alpha_{g} \rho_{g}\right)+\nabla \cdot\left(\alpha_{g} \rho_{g} \vec{v}_{g}\right)=\sum_{i=1}^{n} \dot{M}_{i}$

The momentum conservation equation of gas phase is given with additional terms considering interphase interactions and momentum exchange by mass transfer. $I$ is the momentum exchange due to interaction of gas and solid phases while $R$ is related to interphase mass exchange:

$\frac{\partial}{\partial t}\left(\alpha_{g} \rho_{g} \vec{v}_{g}\right)+\nabla \cdot\left(\alpha_{g} \rho_{g} \vec{v}_{g} \vec{v}_{g}\right)=-\alpha_{g} \nabla p+\nabla \cdot \overline{\bar{\tau}}_{g}+\alpha_{g} \rho_{g} \vec{g}+R+I$

The tress-stain tensor $\overline{\bar{\tau}}_{\mathrm{g}}$ is given as 
$\overline{\bar{\tau}}_{g}=\alpha_{g} \mu_{g}\left(\nabla \vec{v}_{g}+\nabla \vec{v}_{g}^{T}\right)-\frac{2}{3} \alpha_{g} \mu_{g} \nabla \cdot \vec{v}_{g} \overline{\bar{I}}$

The enthalpy equation is introduced to represent the energy conservation of gas phase:

$\frac{\partial}{\partial t}\left(\alpha_{g} \rho_{g} \psi_{g}\right)+\nabla \cdot\left(\alpha_{g} \rho_{g} \psi_{g} \vec{v}_{g}\right)=-\alpha_{g} \frac{\partial p_{g}}{\partial t}+\overline{\bar{\tau}}_{g}: \nabla \vec{v}_{g}-\nabla \cdot q_{g}-\Delta \dot{H}_{g}+S_{g}$

where $\psi_{g}$ is the specific enthalpy of gas phase. The heat transfer between the solid phase and the gas phase is considered by the last term on the right-hand side of Eq. (5), and $\Delta \dot{H}$ is the source term for heat of reactions.

\section{Solid Phase.}

Mass balance equations of the solid phase are of the similar form with the gas phase:

$\frac{\partial}{\partial t}\left(\alpha_{s} \rho_{s} Y_{j}\right)+\nabla \cdot\left(\alpha_{s} \rho_{s} \vec{v}_{s} Y_{j}\right)=\dot{M}_{j}$

$\frac{\partial}{\partial t}\left(\alpha_{s} \rho_{s}\right)+\nabla \cdot\left(\alpha_{s} \rho_{s} \vec{v}_{s}\right)=\sum_{j=1}^{m} \dot{M}_{j}$

where $\alpha_{s}, \rho_{s}, Y_{j}, \vec{v}_{s}, \dot{M}_{j}$ are the local mass fraction, density, velocity of solid and the net production rate of species $\mathrm{j}, \mathrm{j}=1,2, \ldots, \mathrm{m}$, respectively.

Conservation of momentum:

$\frac{\partial}{\partial t}\left(\alpha_{s} \rho_{s} \vec{v}_{s}\right)+\nabla \cdot\left(\alpha_{s} \rho_{s} \vec{v}_{s} \vec{v}_{s}\right)=-\alpha_{s} \nabla p-\nabla p_{s}+\nabla \cdot \overline{\bar{\tau}}_{s}+\alpha_{s} \rho_{s} \vec{g}-I-R+S$

$\overline{\bar{\tau}}_{s}=\alpha_{s} \mu_{s}\left(\nabla \vec{v}_{s}+\nabla \vec{v}_{s}^{T}\right)+\alpha_{s}\left(\xi_{s}-\frac{2}{3} \mu_{s}\right) \nabla \cdot \vec{v}_{s} \overline{\bar{I}}$

where $S$ is the momentum exchange between the solid phases. The solids shear $\left(\mu_{s}\right)$ [21] and bulk viscosities $\left(\xi_{s}\right)$ [22], are used to calculate the solids stress tensor, $\overline{\bar{\tau}}_{s}$.

Conservation of energy:

$\frac{\partial}{\partial t}\left(\alpha_{s} \rho_{s} \psi_{s}\right)+\nabla \cdot\left(\alpha_{s} \rho_{s} \psi_{s} \vec{v}_{s}\right)=-\alpha_{s} \frac{\partial p_{s}}{\partial t}+\overline{\bar{\tau}}_{s}: \nabla \vec{v}_{s}-\nabla \cdot q_{s}-\Delta \dot{H}_{s}-S_{g}$

where $\psi_{s}$ is the specific enthalpy of solid phase.

The governing and constitutive equations are solved by using the finite volume method (FVM). Based on the studies reported in ref. [23,24], the grid size in the order of 10 particle diameters could produce grid independent results. The computational domain given in Figure 1 is discretized with the grid size of $3 \mathrm{~mm}$ at the lower region and of $5 \mathrm{~mm}$ for the rest. No-slip condition is defined for gas on the wall and the free slipping condition is for solids. The SIMPLE algorithm is used for pressure-velocity coupling while the upwind scheme for the discretization of convective terms. All 
simulations are carried out for a real time of $40 \mathrm{~s}$ with the time-step size of $0.0001 \mathrm{~s}$.

\subsection{Intra-particle heat penetration}

Intra-particle heat conduction of large size particles cannot be ignored because the conductive process affects the temperature distribution and then the chemical reactions. Due to the limitation of Eulerian approaches, tracking the internal phenomena of particles seems to be difficult or impossible. The indirect method by applying the effect of heat penetration on the reacting rate is proposed [18]. The temperature distribution and internal particle heat transfer are not represented directly whereas the modifications on the rate constants are given to show the consequence of intra-particle heat penetration. The details are given as follows:

$1 / k^{\prime}=1 / k+1 / k_{h p}$

where $k$ is the rate constant, $k^{\prime}$ is the modified rate constant and $k_{h p}$ is the heat penetration rate. The heat penetration rate is a function of heat transfer coefficient, $h$, specific surface area, $a_{s s a}$, and specific heat capacity of particles, $C p . k_{h p}$ is given as

$k_{h p}=h a_{s s a} / C p$

\subsection{Case setup}

In the present work, Cases 1 and 2 with the gas velocity of 0.2 and $0.8 \mathrm{~m} / \mathrm{s}$ respectively are setup and the influence of the superficial velocity of fluidizing gas is carefully studied. To identify the impact of the intra-particle heat penetration on the yields of end-products, modified rate constants are programed and incorporated into simulations where the first step of the reaction scheme is modified in Case 4. As decomposition of the pseudo-components to actives are quick or instant, the heat conduction effects applied on the first step may be seriously underestimated. Therefore Case 5 is set up by modifying the kinetics on the second step, from the actives to syngas, char and tar. The original kinetics in Figure 2 is employed in Case 3 with no consideration of heat conduction inside the biomass particles. 


\section{Results and discussion}

\subsection{Effects of different superficial velocities}

Detailed studies have been carried out to investigate the relationship between hydrodynamics of fluidized beds and chemical reactions. Figure 3 shows the flow patterns of fluidized beds at $40 \mathrm{~s}$ with different superficial velocities. It is clear that the bed voidage increases with the increasing superficial velocity. Small bubbles are distinct in the bed in Figure 3a where the classical bubbling fluidization presents at the velocity of $0.2 \mathrm{~m} / \mathrm{s}$. The bubble size is much bigger in Figure $3 \mathrm{~b}$ which indicates the fluidization state is transforming to turbulent fluidization at the velocity of 0.8 $\mathrm{m} / \mathrm{s}$.

The by-product, char, has been reported as a catalyst to speed up tar cracking. Fast removal of char to reduce the contacting time of char and tar is supposed to be effective on restraining the secondary cracking during biomass fast pyrolysis. Therefore, the superficial velocity has to be considered referring to not only the heat exchange process but also the holdup of char particles. Figure 4 shows the char volume-fractional distributions of Cases 1 and 2. The color contours represent the char condensation at $40 \mathrm{~s}$ when the fluidizing gas is injected at the velocities of 0.2 $\mathrm{m} / \mathrm{s}$ in Figure $4 \mathrm{a}$ and at $0.8 \mathrm{~m} / \mathrm{s}$ in Figure $4 \mathrm{~b}$. The simulation results display that no reacting particles escapes from the outlet in Case 1 because the terminal velocity of the char particles, bigger than $0.6 \mathrm{~m} / \mathrm{s}$ is higher than the superficial velocity. Meanwhile the segregation phenomena are visual in Figure 4a. The equilibrium of mixing and segregation is broken at high gas velocity as shown in Figure 4b. Correspondingly, the entrained-flow behavior leads to the low instant remaining of char particles in beds.

Figure 5 gives the time-mean yield ratios of syngas over tar from 20-40 s in Cases 1 and 2. According to the simulation results, more syngas is produced at the higher fluidization intensity which delivers the bigger syngas-tar ratio in Case 2. It indicates that the higher fluidization intensity with the higher bed voidage can weaken the heat exchange between the biomass samples and fluidized bed, and the prolonged heating 
up process will affect the yield of tar, subsequently. The results prove that the flow pattern has a significant and complicated connection with the yields of end-products.

\subsection{Consideration of intra-particle heat penetration}

Figure 6 shows the time-mean fractional distributions of the end-products from 20-40 s in Cases 3, 4 and 5. In Case 3, the heat conduction inside the particles is not considered meanwhile the heat penetration model is applied into the biomass degrading scheme: on the first step in Cases 4 but on the second step in Case 5, respectively. Compared to the data of Case 3 in Figure 6, a slight decrease of the tar production can be observed and more char is predicted in Case 4. In Case 5, the visible increase of char yield is achieved by consuming a considerable amount of tar and a few syngas. All of the simulation results show that the internal heat penetration process will give influences on the fractional distribution of end-products. In other words, increasing particles size during biomass pyrolysis in a fluidized bed will produce more char and syngas.

The yields of end-products listed at Table 3 were reported in ref. [19]. With the increase of particle size in Work 1 and Work 2, the yield of oil (tar) decreases from $41.67 \%$ to $39.58 \%$. However more char is produced from $13.33 \%$ to $14.58 \%$ with a slight raise of syngas production. By comparing Case 3 to Case 4 in Figure 6, the yield of tar decreases from $64.5 \%$ to $60.3 \%$ whilst that of char increases from $16.3 \%$ to $20.4 \%$. The variations of end-product fractional distributions, which are supposed to be derived from the intra-particle heat conduction, are in consistence between the simulation results and experimental data, qualitatively. However more tar yields are predicted in the simulations than that reported experimentally in ref.[19]. It can be attributed to several reasons including the operation conditions of the reactor, neglecting the ash composition of biomass, given values of the reaction scheme, etc. The results indicate that the intra-particle heat penetration model is valid to describe the internal heat conduction but the accuracy on end-product yield prediction needs to be improved. 


\section{Conclusions}

A series of studies on impact of mass \& heat transfer on biomass thermal decomposition have been carried out numerically. To investigate the effect of heat transfer on the yield fractional distribution of end products in depth, intra-particle heat penetration is described by an empirical correlation and the heat conduction on the particle scale can be considered with Eulerian approaches. CFD modeling of fast pyrolysis of corn stalk in a bubbling fluidized bed is studied numerically by the Eulerian-Eulerian model. The simulation results show that the superficial velocity of fluidizing gas has to be designed carefully to balance the heating up rate and contacting time between tar and char. The rapid removal of char from reactor will reduce the secondary cracking of tar. However it affects the heating up of biomass samples and the consequent tar yield; effect of heat conduction inside particles on end-product yield distribution is investigated indirectly by modifying the reaction rate constants of the reaction schemes. The consistence between the simulations and experiments proves that the heat penetration model is effective to describe the influence of intra-particle heat conduction. Meanwhile the detailed reaction schemes of biomass fast pyrolysis needs to be proposed to improve the accuracy on the prediction of end-product yields.

\section{Acknowledgements}

The authors are grateful for the support by the Scientific Research Fund for Ph.D. of Northeast Dianli University (Grant No. BSJXM-201509).

\section{References}

[1] A.V. Bridgwater, D. Meier, D. Radlein, An overview of fast pyrolysis of biomass, Organic Geochemistry, 30 (1999) 1479-93.

[2] C. Di blasi, Modeling chemical and physical processes of wood and biomass pyrolysis, Progress in Energy and Combustion Science, 34 (2008) 47-90.

[3] Peng WM, Wu QY. Production of fuels from biomass pyrolysis, New Energy Source. 22 (2000) 39-44.

[4] A. Oasmaa, S. Czernik. Fuel oil quality of biomass pyrolysis oils-state of the art for the end-users, Energy\& Fuels, 13 (1999) 914-21. 
[5] Q. Xue, T.J. Heindel, R.O. Fox, A CFD model for biomass fast pyrolysis in fluidized-bed reactors, Chemical Engineering Science, 66 (2011) 2440-52.

[6] Q. Xue, D. Dalluge, T.J. Heindel, R.O. Fox, R.C. Brown, Experimental validation and CFD modeling study of biomass fast pyrolysis in fluidized-bed reactors, Fuel, 97 (2012) 757-69.

[7] D. Lathouwers, J. Bellan, Modeling of dense gas-solid reactive mixtures applied to biomass pyrolysis in a fluidized bed, Int J Multiphase Flow, 27 (2001) 2155-87.

[8] K. Papadikis, S. Gu, A.V. Bridgwater, 3D simulation of the effects of sphericity on char entrainment in fluidized beds, Fuel Processing Technology, 91 (2010) 749-58.

[9] K. Papadikis, S. Gu, A.V. Bridgwater, CFD modelling of the fast pyrolysis of biomass in fluidised bed reactors: Modelling the impact of biomass shrinkage, Chemical Engneering Journal, 149 (2009) 417-27.

[10] K. Papadikis, S. Gu, A.V. Bridgwater. Computational modelling of the impact of particle size to the heat transfer coefficient between biomass particles and a fluidised bed, Fuel Processing Technology, 91 (2010) 68-79.

[11] K. Papadikis, S. Gu, A.V. Bridgwater, H. Gerhauser, Application of CFD to model fast pyrolysis of biomass. Fuel Processing Technology, 90 (2009) 504-12.

[12] P. Mellin, Q. Zhang, E. Kantarelis, W. Yang, An Euler-Euler approach to modelling biomass fast pyrolysis in fludized-bed reactors-Focusing on the gas phase, Applied Thermal Engineering, 58 (2013) 344-53

[13] P. Mellin, E. Kantarelis, W. Yang, Computational fluid dynamics modeling of biomass fast pyrolysis in a fluidized bed reactor, using a comprehensive chemistry scheme, Fuel, 117 (2014) 704-15.

[14] P. Ranganathan, S. Gu, Computational fluid dynamics modeling of biomass fast pyrolysis in fluidised bed reactors, focusing different kinetic schemes, Bioresource Technology, 213(2016) 333-341.

[15] Q. Xiong, F. Xu, E. Ramirez, S. Pannala, S. Daw, Modeling the impact of bubbling bed hydrodynamics on tar yield and its fluctuations during biomass fast pyrolysis, Fuel, 164(2016) 11-17.

[16] Q. Xue, R.O. Fox, Computational modeling of bimass thermochemical conversion in fluidized beds: particle density variation and size distribution, I\&EC, 54 (2015) 4084-94

[17] T. Henrik, L. Bo, Thermal conductivity of wood-models for different stages of combustion, biomass and bioenergy, 23 (2002) 47-54.

[18] M. Van de Velden, J. Baeyens, I. Boukis, Modeling CFB biomass pyrolysis reactors, Biomass and Bioenergy, 32 (2008) 128-39.

[19] R.H. Liu, C.J. Shen, J.W. Wang, Effect of particle size of corn stalk fast pyrolysis on physicochemical properties of bio-oil, Journal of Biobased Material and Bioenergy, 4 (2010) 1-6.

[20] D. Gidaspow, R. Bezburuah, J.Ding, Hydrodynamics of circulating fluidized beds: Kinetic theory approach, The 7th Fluidization Conference 1992.

[21] M. Syamlal, T.J. O'Brien. Derivation of a drag coefficient from velocity-voidage correlation, Morgantown, Virginia: US dept of Energy, Office of Fossil Energy, National Energy Technology Lab; 1987.

[22] C.K.K. Lun, S.B. Savage, D.J. Jeffrey, N. Chepurniy, Kinetic theories for granular 
flow: inelastic particles in couette flow and slightly inelastic particles in a general flow field, J Fluid Mech, 140 (1984) 223-56.

[23] T. Li, J. Grace, X. Bi, Study of wall boundary condition in numerical simulations of bubbling fluidized beds, Powder Technology, 203(2010) 447-457.

[24] J. Min, J.B. Drake, T.J. Heindel, R.O. Fox, Experimental validation of CFD simulation of a lab-scale fluidized-bed reactor with and without side-gas injection, AIChE Journal, 56(2010) 1434-46. 
Table 1

Gas and solid physical property

\begin{tabular}{clll}
\hline Property & Value & Unit & Comment \\
\hline$\rho_{\text {bio }}$ & 400 & $\mathrm{~kg} / \mathrm{m}^{3}$ & biomass density \\
$\rho_{\text {cha }}$ & 200 & $\mathrm{~kg} / \mathrm{m}^{3}$ & char density \\
$\rho_{\text {san }}$ & 2500 & $\mathrm{~kg} / \mathrm{m}^{3}$ & Sand density \\
$C p_{\text {cha }}$ & 1100 & $\mathrm{~J} / \mathrm{kg} \cdot \mathrm{K}$ & Heat capacity \\
$C p_{\text {san }}$ & 835 & $\mathrm{~J} / \mathrm{kg} \cdot \mathrm{K}$ & Heat capacity \\
$\mu_{n_{2}}$ & $3.58 \mathrm{e}-5$ & $\mathrm{~Pa} \cdot \mathrm{s}$ & Viscosity \\
$\lambda_{\text {bio }}$ & 0.105 & $\mathrm{~W} / \mathrm{m} \cdot \mathrm{K}$ & Heat conductivity \\
$\lambda_{\text {cha }}$ & 0.071 & $\mathrm{~W} / \mathrm{m} \cdot \mathrm{K}$ & Heat conductivity \\
$\lambda_{\text {san }}$ & 0.35 & $\mathrm{~W} / \mathrm{m} \cdot \mathrm{K}$ & Heat conductivity \\
$d_{\text {bio }}$ & 0.4, & $\mathrm{~mm}$ & Diameter \\
$d_{\text {san }}$ & 0.4 & $\mathrm{~mm}$ & Diameter \\
\hline
\end{tabular}


Table 2

Reaction constants of chemical kinetics of biomass pyrolysis[7]

\begin{tabular}{|c|c|c|c|}
\hline Rate constant & $A_{i}(1 / s)$ & $E_{i}(\mathrm{~J} / \mathrm{kmol})$ & Char yield (\%) \\
\hline$k_{1, \mathrm{cel}}$ & $2.8 \times 10^{19}$ & $2.424 \times 10^{8}$ & \\
\hline$k_{2, \mathrm{cel}}$ & $3.28 \times 10^{14}$ & $1.965 \times 10^{8}$ & \\
\hline$k_{3, \mathrm{cel}}$ & $1.30 \times 10^{10}$ & $1.505 \times 10^{8}$ & \\
\hline$\chi_{c e l}$ & & & 0.35 \\
\hline$k_{1, \text { hem }}$ & $2.10 \times 10^{16}$ & $1.867 \times 10^{8}$ & \\
\hline$k_{2, \text { hem }}$ & $8.75 \times 10^{15}$ & $2.024 \times 10^{8}$ & \\
\hline$k_{3, \text { hem }}$ & $2.60 \times 10^{11}$ & $1.457 \times 10^{8}$ & \\
\hline$\chi_{c e l}$ & & & 0.6 \\
\hline$k_{1, l i g}$ & $9.60 \times 10^{8}$ & $1.076 \times 10^{8}$ & \\
\hline$k_{2, l i g}$ & $1.50 \times 10^{9}$ & $1.438 \times 10^{8}$ & \\
\hline$k_{3, l i g}$ & $7.70 \times 10^{6}$ & $1.114 \times 10^{8}$ & \\
\hline$\chi_{c e l}$ & & & 0.75 \\
\hline$k_{4}$ & $4.28 \times 10^{6}$ & $1.08 \times 10^{8}$ & \\
\hline
\end{tabular}


Table 3

Fractional distributions of end-products[19]

\begin{tabular}{|c|c|c|c|c|}
\hline \multirow{2}{*}{ No. } & \multirow{2}{*}{$\begin{array}{l}\text { Particle size } \\
(\mathrm{mm})\end{array}$} & \multicolumn{3}{|c|}{ Yield of end-products (wt\%) } \\
\hline & & $\operatorname{tar}$ & char & syngas \\
\hline Work 1 & $<0.45$ & 41.67 & 13.33 & 45 \\
\hline Work 2 & $0.45 \sim 0.6$ & 39.58 & 14.58 & 45.84 \\
\hline
\end{tabular}




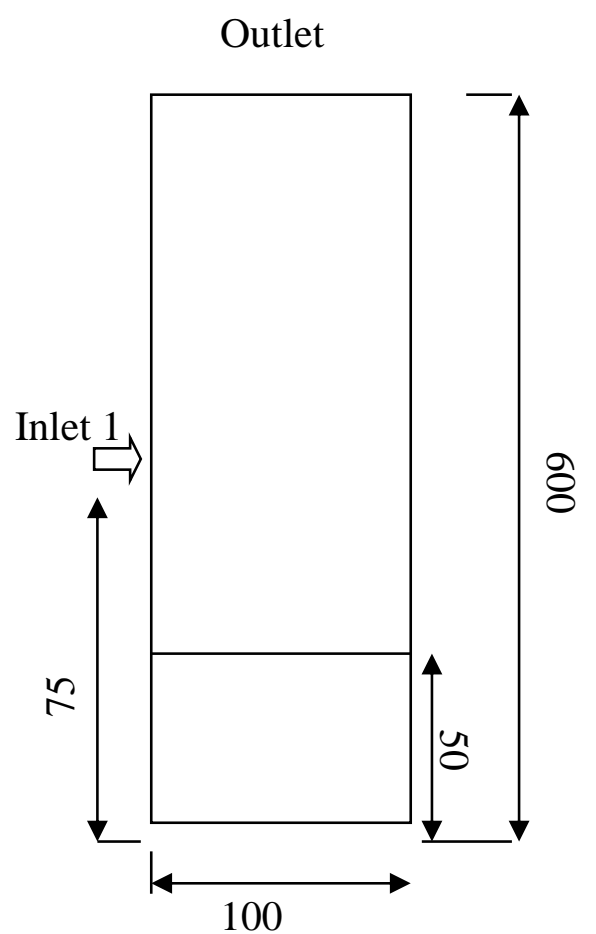

Figure 1. Schematic of the fluidised bed reactor 


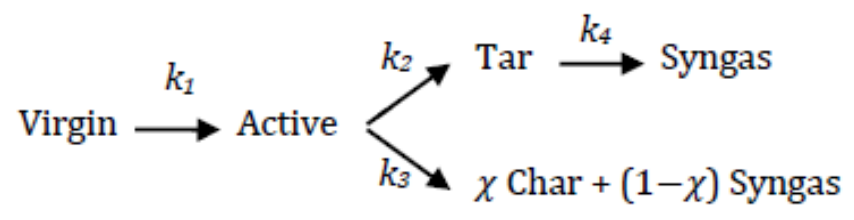

Figure 2. Reaction sheme of biomass fast prolysis 


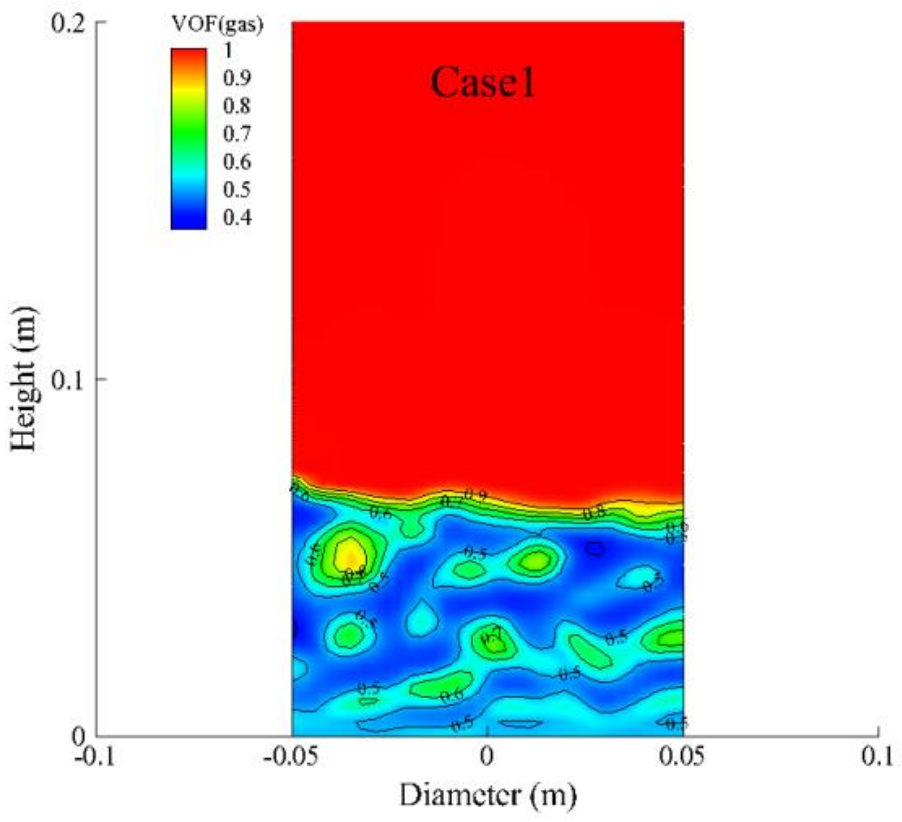

a

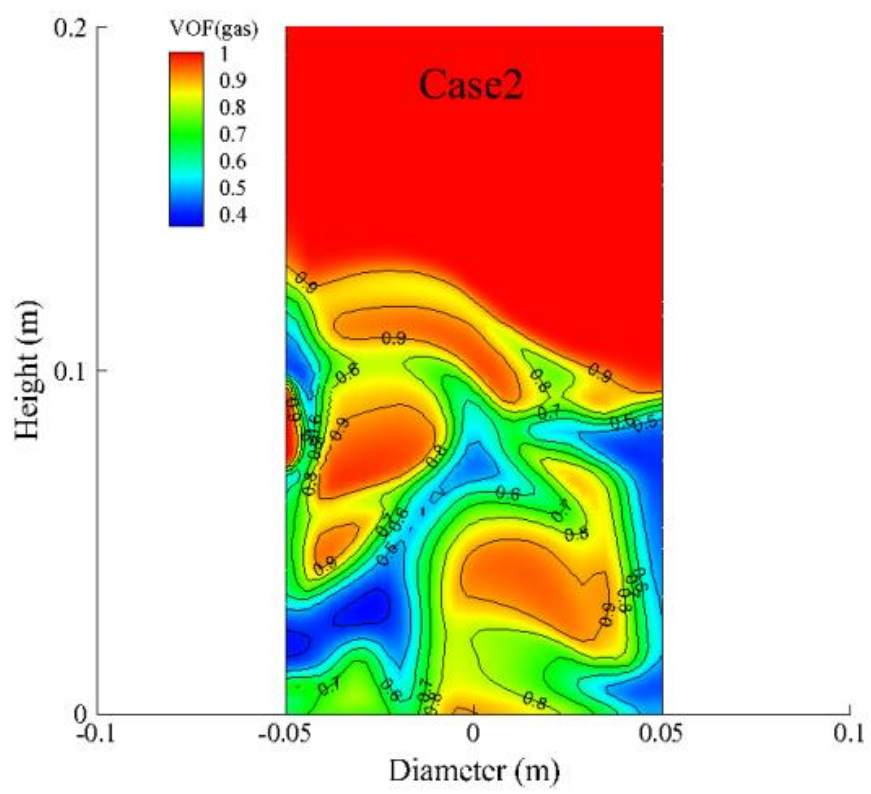

b

Figure 3. flow patterns of the fluidized beds: a.Case 1; b. Case 2 


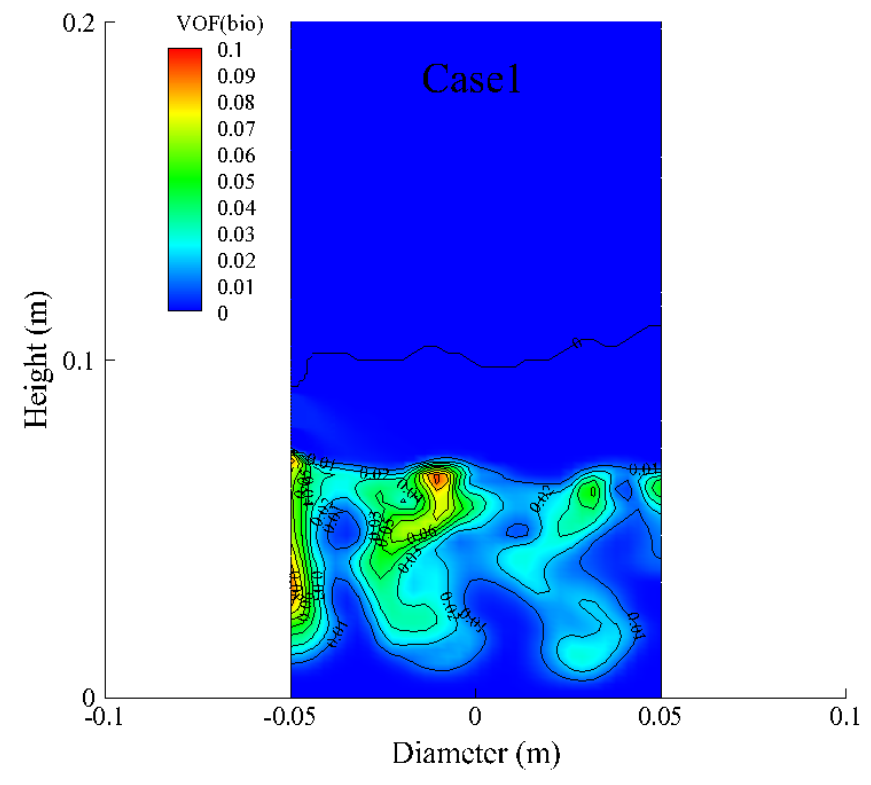

a

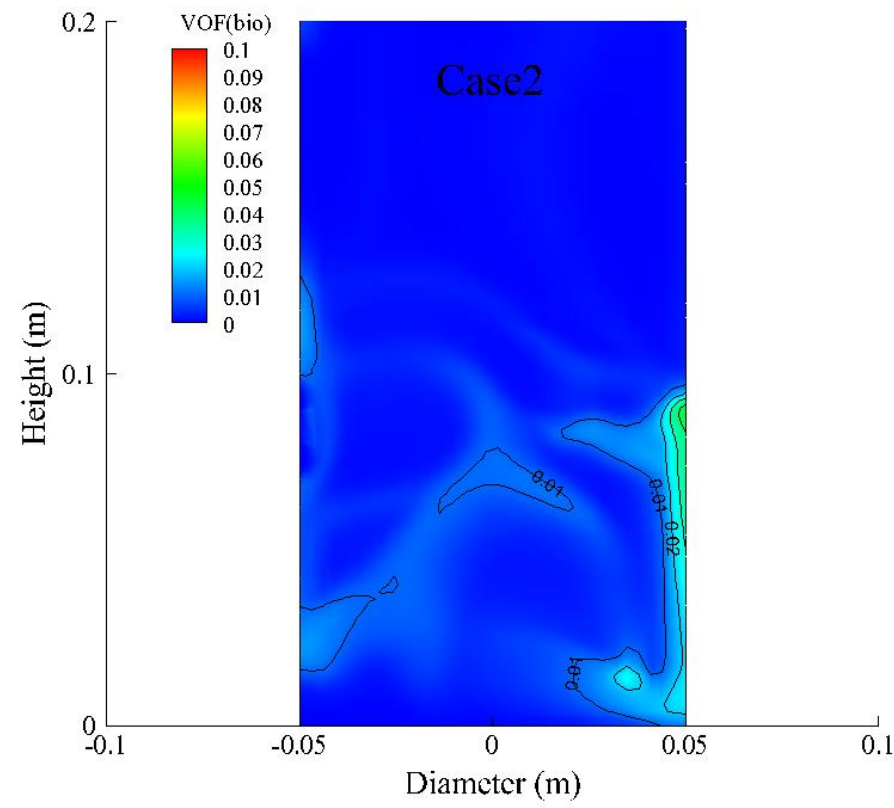

b

Figure 4. Biomass distributions in the fluidized beds: a.Case 1; b. Case 2 


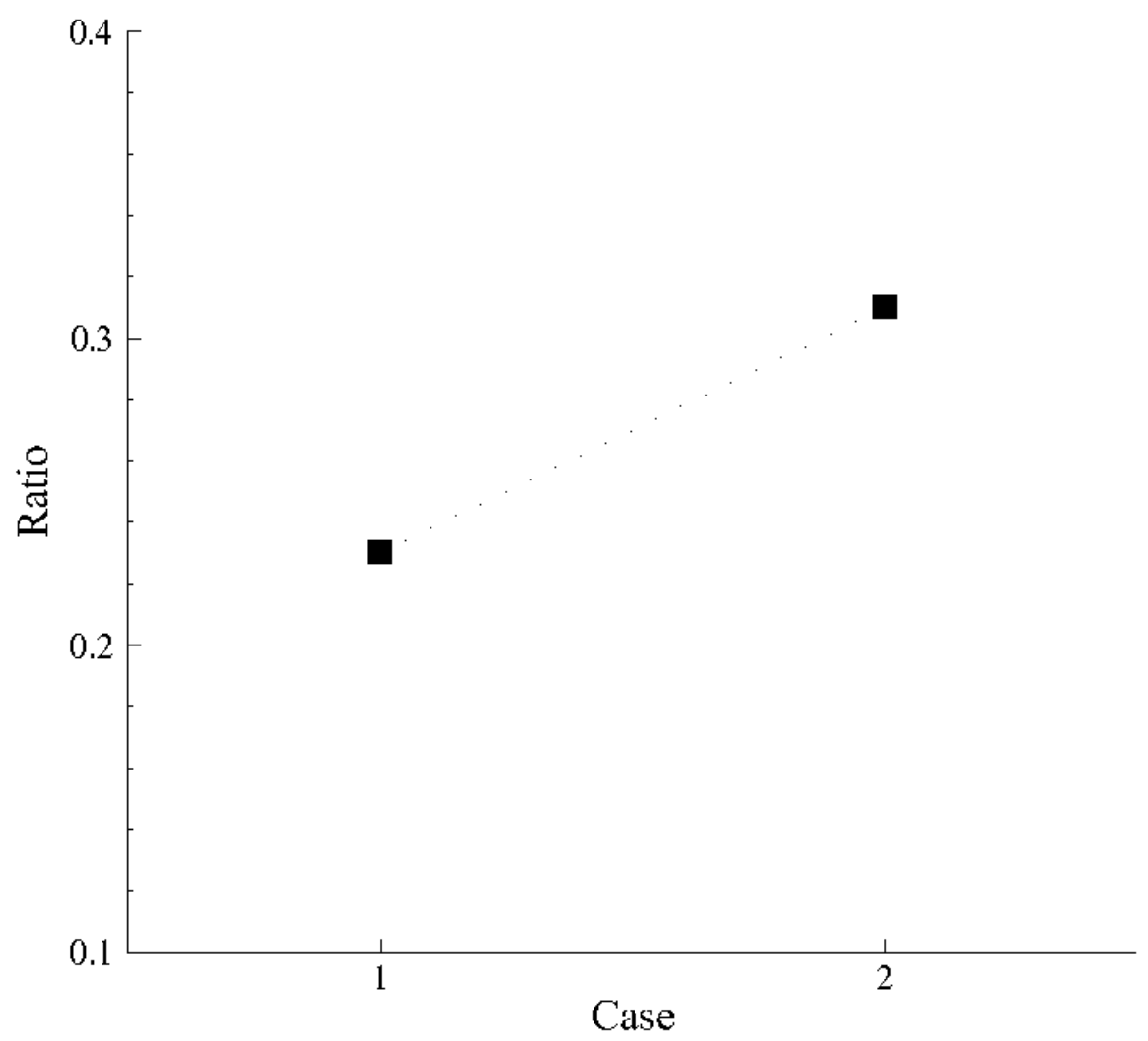

Figure 5. Ratio of syngas over tar at the outlets of fluidized beds 


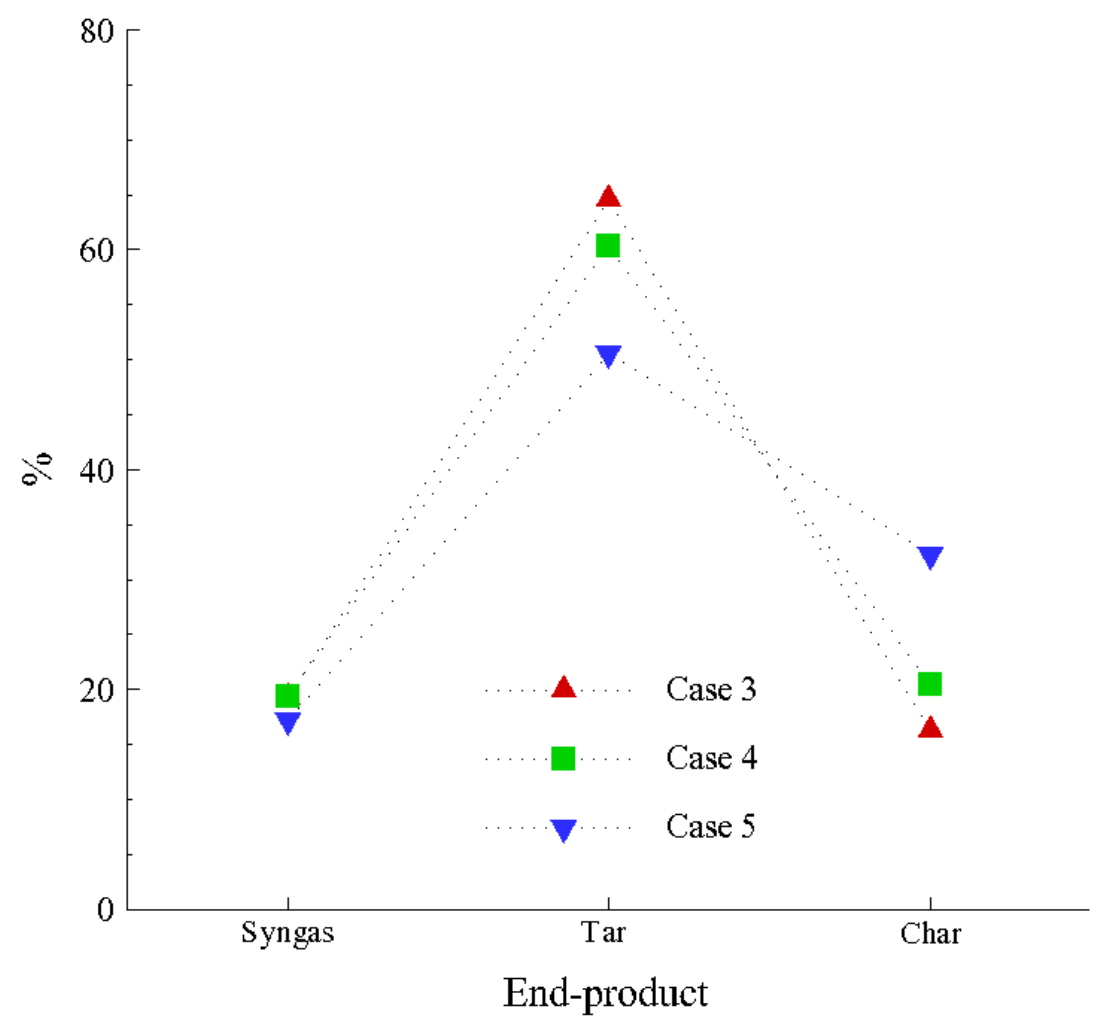

Figure 6. Fractional distributions of the end-products at the outlets of fluidized beds 